\section{Senhor Editor,}

Dirijo-me a V.S ${ }^{\mathrm{a}}$, para tecer alguns comentários ao artigo "Cardiologia no lúpus eritematoso sistêmico" publicado no vol 68; 2: 79-83. As Sociedades de Reumatologia criaram modelos de atividade (lesões reversíveis) e severidade (lesões irreversíveis) do lúpus para que exista uma linguagem única, evitando-se classificações inapropriadas. Hoje temos dezenas (64) de índices de atividade lúpica, entretanto, os mais usados são o Sledai e Bilag. Os autores não referiram qual destes protocolos de atividade foi utilizado, dificultando uma melhor análise ao leitor. Nota-se falta de orientação no desenho do trabalho, quando refere que os exames foram avaliados por observador independente (sem conhecimento), mas estes mesmos exames foram avaliados por um outro observador e comparado o grau de concordância entre ambos?

Finalmente, $\mathrm{o}$ apoio dado pelo CNPq deveria ser mais rigoroso, pois algumas pesquisas não acrescentam nada ao que já se sabe na literatura mundial.

\section{Prof. Dr. Fernando de Souza Cavalcanti Disciplina de Reumatologia - UFPE}

\section{Senhor Editor,}

Em nome dos autores do artigo "Avaliação clínica e laboratorial da cardiopatia no lúpus eritematoso sistêmico" (Arq Bras Cardiol 1997; 68: 79-83) e em resposta à carta ao Editor do Dr Fernando de Souza Cavalcanti, faço os seguintes comentários. Não há hoje, assim como no início da coleta de dados de nossos pacientes, um consenso a respeito do melhor índice de atividade em pacientes lúpicos. Atualmente, o mais utilizado destes índices em estudos de prognóstico no lúpus tem sido o Sledai (Arthritis \& Rheum 1992; 35: 630-40). Em nosso estudo, a caracterização de atividade lúpica foi feita pela presença de sintomas e sinais da doença associada à positividade de células LE ou anti-DNA e diminuição de complemento como está assinalado na seção "Métodos" do artigo à página 80. As imagens e traçados obtidos foram analisados por observador independente, ou seja, sem conhecimento do quadro clínico do paciente. As mesmas imagens e traçados foram também analisados e interpretados pelo serviço de diagnóstico por imagem e pelo médico assistente do paciente e, quando houve discordância, optou-se pela interpretação do observador sem conhecimento do caso. $\mathrm{O}$ que se sabe na literatura mundial sobre a associação de manifestações cardíacas no lúpus e presença de anticardiolipina no soro se deve em grande parte aos estudos do Dr Khamashta, da Lupus Clinic de Londres. Este por meio de estudo multicêntrico (referência 25 do artigo), realizado nos serviços da Inglaterra, Espanha e Holanda, verificou haver associação entre valvulopatia lúpica e positividade de anticorpo anticardiolipina no soro e especula sobre a importância patogênica desta associação. Nosso estudo, assim como os de Gonçalves (referência 37 do artigo) e de Li e col (referência 38 do artigo) mostram não haver associação entre presença de anticardiolipina no soro e lesões cardíacas no lúpus. Estes fatos implicam a necessidade de novos estudos, multicêntricos, com maior número de casos, para verificar da possibilidade desta associação cardiopatia lúpica e anticardiolipina. Em tempo, acreditamos que as bolsas de iniciação científica do CNPq aos alunos de graduação em Medicina que participaram deste estudo foram bem utilizadas.

\section{Prof. Dr. Gilberto Santos Novaes Disciplina de Reumatologia da PUC-SP}

\section{Senhor Editor,}

Algumas grandes revistas recusam publicar artigos do tipo "relato de caso" pela absoluta incapacidade de tornálos uma verdade científica. Não obstante, os que defendem sua existência, argumentam que situações raras ou condutas inéditas podem servir de "pontapé inicial" para que grandes estudos multicêntricos ou em grandes instituições possam ser desenhados buscando validá-los. À margem destes objetivos maiores, a vontade de divulgar sua experiência incomum ou, em grau mais baixo, de exibir vaidades faz, deste tipo de publicação, um risco para a credibilidade da publicação. Para minimizar estes riscos, a revista deve ter normas de grande rigor e exigir dos autores um perfeito alinhamento para alcançar o mérito de ter seu relato publicado.

Todas estas considerações me vieram à mente após a leitura atenta do relato de Viana e col sobre o uso de stent em caso de choque cardiogênico (Arq Bras Cardiol 1996; 67: 343-6) e gostaria de apresentar dois pontos para discussão que acho relevantes, no sentido de associarmos aprendizado à informação. O primeiro é se há mérito em publicá-lo e quais as exigências para fazê-lo. Na minha opinião justificase sua publicação, pois, como descrito na introdução do artigo, é discutível o uso de stents intracoronários em situações clínicas agudas, mais ainda no tronco da coronária esquerda (TCE) e, pior, em choque cardiogênico. Mas, acho que é responsabilidade do Conselho Editorial da revista algumas críticas prévias à sua aceitação para que tenhamos um relato de caso completo e com informação de alto nível. Senão vejamos:

Questões simples mas essenciais de metodologia para descrição de caso clínico como a identificação do sexo (feminino, sabemos pelo abstract ou no fluxo do texto); a ausência de explicação para a não revascularização da artéria DA em um caso de TCE; a omissão de referência sobre o estado de todas as pontes de safena (PS) no estudo logo após a cirurgia (deduzimos que estão ocluídas, exceto a da $\mathrm{CD}$ ); a falta de explicação (não se tem nem curiosidade?) de por que, em um caso de sucesso e com evolução sem ne- 
nhuma intercorrência descrita, a paciente permaneceu 21 dias internada!? Ainda, não foi exigida uma revisão dos dados da cine após seis meses quando, na tabela I, é descrita uma lesão de 46,9\% aparentemente considerando o mesmo diâmetro de referência (DR) do exame prévio. Todos que trabalham com angiografia quantitativa sabemos da variação de suas medidas, sendo exigido que seus cálculos sejam tomados na mesma aquisição. No caso específico, um simples erro de $0,2 \mathrm{~mm}$ no DLM encontrado após seis meses (variação de 11\%) diagnosticaria reestenose ainda mais em se tratando de TCE. O texto todavia, afirma que houve "manutenção do resultado inicial". E se há uma perda tardia quase bordeline para o stent, como estará o resultado da ATC na PS para a CD, cujo resultado não foi descrito pelos autores nem exigido pela revisão editorial?

O $2^{\circ}$ ponto é o que podemos aprender com o relato e aplicá-lo à nossa prática. Ao lermos um artigo como este $\mathrm{e}$ de um grupo que tão reconhecida experiência, ficamos com a tentação de reproduzí-lo, mas...devemos? É a melhor conduta em um caso de choque cardiogênico realizarmos dois procedimentos em um só tempo, sem nem ao menos dispormos de um dispositivo de assistência circulatória? E, questões técnicas mas essenciais, podemos prescindir de uma hiperinflação do stent, nos tempos atuais, apenas com a informação angiográfica?

Com o objetivo de não desperdiçarmos esta valiosa chance de debate e para que estas questões sejam efetuadas na ocasião adequada e não fiquem sem respostas, sugiro que ao lado de cada relato de caso sobre condutas, seja publicada a opinião de um especialista que, ao exercitar a crítica, estimule o debate e a reflexão e, assim, possamos extrair aprendizado e não apenas informação.

\section{Dr. Jorge Augusto N. Guimarães Hospital Português - Recife, PE}

\section{Senhor Editor,}

Tomamos conhecimento da carta do Dr. Jorge Augusto N. Guimarães sobre a qual gostaria de solicitar à V.Sa. um espaço para os seguintes comentários: 1) o Dr. Guimarães faz uma insinuação que apesar de velada nos causou surpresa. Nesses 32 anos de exercício e ensino da especialidade, não havíamos jamais vislumbrado a possibilidade de alguém utilizar o espaço da revista para simples satisfação do sentimento de vaidade. Assim, esperamos que a intenção do Dr. Guimarães não seja a de nos julgar, porém, o honesto intuito de melhorar a qualidade da apresentação de um relato de caso; 2) os Arquivos Brasileiros de Cardiologia são uma revista de Cardiologia Clínica e, como tal segue uma orientação de resumir ao máximo os aspectos técnicos. Neste contex to o relato publicado (Arq Bras Cardiol 1996; 67:343-6), foi aprovado pelo Conselho Editorial com qualificações científicas acima de qualquer questionamento, 3) por maior que seja o cuidado na revisão da forma, fatos como a descrição do sexo do paciente, tão enfatizado, podem passar despercebidos; 4) pelas peculiaridades clínicas e anatômicas que levaram a paciente a uma situação de morte iminente e a sua reversão, pelo acerto de conduta numa situação de exceção, pelos ensinamentos que a paciente nos proporcionou, solicitamos ao Dr. Watson a sua divulgação; 5) sendo cardiologista intervencionista como o Dr. Guimarães, solicitamos à V.Sa. a permissão para complementar a apresentação do caso sob nossa visão.

Paciente, irmã de um médico, submeteu-se à cirurgia de revascularização miocárdica em 2/10/94, apresentando novamente quadro clínico de angina instável. A cirurgia tinha sido indicada pela presença de uma lesão obstrutiva de 95\% no tronco da artéria coronária esquerda (TCE); lesão obstrutiva de $75 \%$ na porção inicial da artéria circunflexa (Cx) e obstrução de $80 \%$ na artéria coronária direita (CD), sendo o ventrículo esquerdo normal. Foi planejada a cirurgia de revascularização miocárdica com ponte de veia safena (PVS) para a artéria descendente anterior (DA), Cx e CD. Durante o ato cirúrgico não foi possível realizar a anastomose para as artérias DA e Cx devido ao seu trajeto intramiocárdico. Frente a esta dificuldade foi feita a anastomose da safena para um pequeno ramo diagonal (Di), ficando desprotegido o restante da circulação coronária esquerda, limitado pela lesão de TCE. Foram realizadas mais duas anastomoses para $\mathrm{CD}$, sendo uma para a artéria descendente posterior (DP) e outra para a artéria ventricular posterior esquerda (VPE) oriunda da $\mathrm{CD}$. A cirurgia decorreu sem intercorrências, porém após a alta a paciente voltou a apresentar dores precordiais, sendo indicada nova cinecoronariografia que revelou: CD ocluída no seu terço distal antes da DP. Oclusão do segmento inicial da VPE.PVS Ao-VPE funcionante; a PVS Ao-DP com lesão obstrutiva, provavelmente cicatricial, de $95 \%$ próximo a anastomose; TCE com obstrução de 95\%; DA com irregularidades; CX com $80 \%$ no terço inicial; PVS Ao-Di funcionante. Após essa cinecoronariografia, a paciente foi encaminhada para tratamento no nosso serviço com o seguinte planejamento: iniciar o procedimento com a dilatação da PVS-DP, seguida de uma implantação do stent em TCE. Conduta baseada no conhecimento acumulado do bom resultado imediato e tardio deste tipo particular de lesão, a da PVS-DP e pela possibilidade de proteger a paciente numa possível complicação durante a manipulação no TCE. A paciente chegou à nossa Unidade de Cardiologia Intervencionista (UCI) em quadro de insuficiência cardíaca congestiva (ICC) classe funcional III, às 21 h no dia 20/11/94.

Com a piora do quadro clínico, apesar da medicação, foi necessário antecipar a intervenção que foi realizada às 14 h do dia 21/11/94, com a paciente em péssimas condições clínicas. O procedimento foi executado, com a velocidade necessária, pela via femoral, utilizando o cateter guia JR4. Logo após a dilatação da PVS-DP com sucesso, foi substituído o cateter guia JR4 pelo JL4 com o qual foi caracterizada a artéria coronária esquerda (CE). Ao injetar o contraste, tivemos a surpresa de verificar a oclusão do TCE, que justificava a piora do quadro clínico. Imediatamente, o TCE foi 
recanalizado e implantado o stent com sucesso pela técnica vigente na época. Após o procedimento, a paciente voltou à UCI onde foi controlada a anticoagulação, a ICC e o diabetes. O tempo total da estadia hospitalar foi longo em decorrência desses controles e da necessidade de tempo para recuperação do miocárdio gravemente comprometido pelo infarto agudo do miocárdio (IAM). A paciente teve alta hospitalar, sendo reestudada em 29/6/95, com o exame demonstrando oclusão da CD, a PVS-DP com lesão obstrutiva de $40 \%$ na porção inicial e $60 \%$ na distal à anastomose. A PVS-VPE estava inalterada. O TCE com obstrução de 50\% na análise visual; DA com irregularidades; a Cx com obstrução de $40 \%$ ePVS-Di inalterada. O ventrículo esquerdo(VE) com hipocontratilidade difusa ++/+++. Para uma melhor definição, solicitamos a análise quantitativa do TCE ao Dr Fausto Feres que a realizou no Instituto Dante Pazzanese de Cardiologia, demonstrando uma lesão obstrutiva intra stent de $46,9 \%$. Este valor não atingiu os níveis estabelecidos para critério de reestenose angiográfica, em geral definido como lesão $\geq 50 \%$. Corroborando com a análise angiográfica a paciente evoluiu sem dor precordial nesse espaço de três anos de evolução. Controla o seu diabetes e a hipertensão, tendo sido necessária sua internação por duas vezes em virtude de crise hipertensiva e edema agudo do pulmão, facilmente corrigido pelo controle da crise hipertensiva.

Gostaríamos de ressaltar alguns tópicos de aprendizado que a paciente nos proporcionou, e que motivou sua divulgação: 1) a possibilidade de tratar com eficiência, em situações de emergência, lesões obstrutivas no tronco da $\mathrm{CE}$, principalmente nos casos onde a cirurgia de revascu- larização está contra-indicada. Deve-se ressaltar, de um lado, que o consenso geral dita ser a cirurgia de revascularização o tratamento ideal. De outro, que apesar do grande desenvolvimento técnico-tecnológico na implantação dos stents, ainda persiste o risco de oclusão subaguda ao redor de $1 \%$; 2) ficou patente a importância do entrosamento das equipes clínica, hemodinâmica e de cirurgia, porquanto se a angioplastia coronária fosse indicada com maior precocidade, após a cirurgia, a paciente não teria corrido o risco de morte iminente; 3 ) a necessidade de analisar com maior cuidado a evolução da paciente, após a internação na UCI. A posteriori julgamos que o tempo gasto na correção da lesão obstrutiva da PVS-DP tenha contribuído para uma maior quantidade de músculo perdido, contribuindo, também, para aumentar o tempo de estadia hospitalar; 4) a possibilidade de atuação da Cardiologia Intervencionista em casos de extrema gravidade como o presente (IAM e choque cardiogênico por oclusão de TCE), apesar da indisponibilidade, transitória, de utilização do balão intraaórtico. O ideal seria ter à disposição esses recursos que indubitavelmente melhorariam os resultados e propiciariam um ambiente de atuação médica mais adequado.

Finalmente, gostaríamos de expressar os nossos agradecimentos ao Conselho Editorial e à V. Sa. por ter dado a oportunidade de registrar a nossa conduta perante os problemas apresentados pela paciente. À paciente e às equipes envolvidas que nos proporcionaram o aprendizado e momentos de reflexão no transcurso do tratamento.

Dr. Siguemituzo Arie
Instituto do Coração do Hospital das Clínicas - FMUSP 